\title{
O risco como recurso para a arbitragem social
}

\author{
MYRIAM MITJAVILA
}

RESUMO: Nas duas últimas décadas, as ciências sociais registraram e analisaram um novo modo de codificar os perigos e as ameaças que caracterizam a vida social nas sociedades contemporâneas, e que consistem na proliferação de discursos e práticas técnico-políticas organizadas em função de uma nova categoria de risco. Podemos observar que existe um consenso na literatura sociológica a respeito da definição de risco como uma construção social e sobre suas relações complexas com o conhecimento técnico-científico. Este trabalho discute as bases sócio-técnicas e institucionais do risco como um instrumento de arbitragem de problemas sociais nos mais diversos níveis como provisão seletiva de serviços sociais, determinação de culpa e/ou perigo no comportamento criminoso, liberação de crédito em instituições financeiras, gerenciamento de recursos humanos na área de trabalho, entre outros.

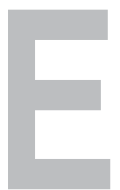

ste trabalho retoma alguns dos resultados de uma pesquisa que teve por finalidade examinar o papel do risco como dispositivo na produção de novas formas de conhecimento e de gestão de problemas no campo médico-sanitário (cf. Mitjavila, 1999). Nesse contexto, uma questão muito específica emergiu como eixo de interesse para incursões posteriores na temática do risco: trata-se da expansão do uso do risco como recurso para arbitragem de situações, principalmente na área do social.

PALAVRAS-CHAVE: risco, novas práticas de saúde, arbitragem social.
Professora do Depto. de Serviço Social da UFSC 
1 Trabalho apresentado no Congresso Internacional: Universal Values and the Future of Society. Mesa: Tecnology, tecnopathies and the meaning of labour Titulo original: Risk: a New Device for Social Arbitration. International Sociological Association / Palas Athena / PUC-SP / SESC-SP /UNESCO. São Paulo, SESC-Vila Mariana, 17 a 19 de setembro de 2001.
As instituições modernas apoiam-se permanentemente em agentes e mecanismos que permitem categorizar indivíduos, famílias ou situações conforme as necessidades de tomar decisões que afetam a vida das organizações, e também das pessoas. Um mapeamento preliminar das formas de arbitragem mais visíveis permite reconhecer a existência de uma grande diversidade de mecanismos e funções sociais que desempenham os árbitros sociais nas sociedades contemporâneas. A arbitragem não é uma ocupação, nem uma profissão: é um tipo de função que diversos agentes institucionais desenvolvem em determinadas áreas e com objetivos muito precisos.

Devido a isso, a questão da arbitragem oferece, na minha opinião, uma perspectiva interessante para estudar o funcionamento das instituições na contemporaneidade. As diversas formas de arbitragem implicam tomar decisões, que com freqüência se apresentam como alternativas dicotômicas em múltiplas circunstâncias. Permitem assim decidir assuntos muito diferentes entre eles como, por exemplo, outorgar ou não outorgar um crédito no sistema financeiro; encaminhar ou não encaminhar uma criança para adoção; determinar se uma pessoa pode ou não ser julgada por um crime ou delito; decidir se uma família deve ou não receber apoio de um programa de assistência social; enfim, a lista seria interminável. O que do ponto de vista deste trabalho interessa sublinhar é a importância que assumem os mecanismos por meio dos quais se realizam essas arbitragens e o que estão nos informando sobre os rumos culturais e os universos de valores da vida social atual.

Sem ser o único mecanismo envolvido, o risco parece permear cada vez com maior força os discursos e as práticas que agem no coração de muitas das circunstâncias de arbitragem social. Cada vez mais decisões de tipo arbitral parecem ser tomadas em nome da exposição a algum tipo de risco ou riscos que afetam tanto os indivíduos como as organizações, ou ainda, no nível da reprodução dos universos simbólicos, as próprias instituições contemporâneas.

Essa diversidade de áreas e circunstâncias nas quais o risco parece intervir pode ser melhor compreendida se forem observados os principais traços que seriam comuns a todas elas. Tratam-se de elementos que contribuem para explicar a enorme expansão do risco como dispositivo de conhecimento e de poder e seu comportamento relativamente uniforme nesses sentidos. Essas dimensões podem ser agrupadas da seguinte forma:

(I) a crescente reflexividade da vida social moderna e a adequação da lógica do risco aos processos de individualização e responsabilização dos agentes sociais individuais;

(II) o desenvolvimento de novas tecnologias baseadas em sistemas de informação que combinam o registro de dados individuais com a gestão tecnocrática das populações (cf. Castel, 1981), assim como suas 
MITJAVILA, Myriam. O risco como recurso para a arbitragem social. Tempo Social; Rev. Sociol. USP, S. Paulo, 14(2): 129-145, outubro de 2002.

conseqüências em termos de uma também nova divisão do trabalho entre os agentes técnicos que participam na fixação de destinos homogêneos para os indivíduos que possuem os mesmos fatores de risco;

(III) a institucionalização do caráter auto-referente do risco como mecanismo de arbitragem social: as decisões passam a ser tomadas, não em função do que efetivamente acontece ou acontecerá, e sim a partir da probabilidade de que algum sucesso - sempre ou quase sempre indesejável - possa ocorrer;

(IV) finalmente, a conversão do risco em instrumento de caráter universal e versátil para dirimir questões sociais, na medida em que responde a uma sintaxe uniforme, propriedade que favorece sua conversão em veículo de múltiplos significados e fins sociais.

\section{O risco e os processos de individualização social}

Referindo-se às relações entre agentes e estruturas sociais, autores como Beck (cf. Lash \& Wynne, 1992) consideram que, quando a modernização atinge um certo nível, diminuem os constrangimentos de natureza estrutural sobre os indivíduos, já que são as próprias forças do processo de mudança estrutural que tornam os atores mais livres com relação à estrutura. Assim, para que a modernização seja bem sucedida nessa fase, os agentes sociais devem eles mesmos se livrar desses constrangimentos como forma de permitir o processo modernizador. Segundo Beck (cf. Lash \& Wynne, 1992), trata-se de uma mudança estrutural da vida privada, baseada na individualização dos agentes privados, os quais estão forçados a tomar decisões sobre si mesmos: com quem casar-se, ter filhos, definir preferências sexuais, etc. Livres de pressões estruturais, os indivíduos devem construir reflexivamente suas próprias biografias. Isso pode ser particularmente observado no mundo do trabalho, o qual apresenta cada vez mais exigências em termos de reestruturação, respostas flexíveis e rápidas, características que incluem também a utilização do tempo livre.

De certo ponto de vista, poder-se-ia concordar com a afirmação de Rosanvallon (1995) de que a modernidade tardia está vinculada a uma inflexão decisiva na percepção do social. Assim, a crise do Estado Providência não implica apenas uma série de mecanismos que enfraquecem, transformam ou suprimem fatores de integração social, como também representam um apelo à responsabilidade dos indivíduos nos processos de gestão dos riscos sociais. Tratam-se de transformações do edifício social que não só alteram as percepções quanto à incerteza, mas também levam a uma relação diferente dos indivíduos com o Estado.

Essa orientação pode ser mais extensamente interpretada como uma transformação global das relações entre os indivíduos e as instituições sociais (cf. Rosanvallon, 1995). E em certa medida, a referida trans- 
formação, por sua vez, pode ser considerada como uma radicalização do padrão introduzido pela modernidade desde seu início, segundo a qual os sujeitos tanto individuais quanto coletivos são submetidos a uma "lógica de mercado" simbólica. A modernidade cria, então, uma situação na qual selecionar e escolher representam verdadeiros imperativos socioculturais: os indivíduos são convocados a recolher e articular os fragmentos de um mundo dilacerado do ponto de vista da significação subjetiva. ${ }^{2}$

Alguns autores concordam em que a modernidade é uma cultura do risco (cf. Douglas, 1990; Giddens, 1995). Esse novo interesse das ciências sociais pela noção de risco é resultado precisamente da necessidade de identificação, tanto das bases quanto das conseqüências sociais de uma nova semântica e práticas sociais em torno das incertezas e perigos da vida contemporânea. Assim, a preocupação pelo risco estaria menos vinculada ao predomínio real ou fatual de diversos tipos de ameaça para a vida humana do que às racionalidades, interesses e padrões culturais que organizam a percepção e as respostas sociais perante esses perigos. (cf. Douglas \& Wildavski, 1982; Giddens, 1995)

Por essa ótica, a questão de risco - e as formas sociais de sua construção - pode informar sobre elementos nucleares da modernidade, destacando-se entre eles o que Giddens denomina colonização do futuro. Esse novo parâmetro temporal está sugerindo a emergência de duas novas dimensões institucionais na crise da modernidade: o fracasso relativo das velhas ou precedentes respostas às ameaças para a vida social (cf. Douglas, 1990), por um lado, e, por outro lado, o caráter produtivo do risco como conceito e como dispositivo suscetível de agir, de maneira flexível, perante os desafios da crise, na gestão da incerteza. Nessa direção, a propriedade imunizadora com relação ao fracasso constitui uma das bases primordiais da versatilidade do risco como conceito. Na medida em que ele opera por intermédio de enunciados sobre o futuro, qualquer medição - em termos de probabilidade e/ou improbabilidade - será fictícia e, por isso, sem compromisso. Assim, os sistemas abstratos -e, especialmente, as disciplinas técnicas, como a medicina, por exemplo desenvolveram-se durante muito tempo mais próximos da administração dos perigos que dos riscos, cada vez que deviam diagnosticar (e predizer) o futuro de situações concretas, únicas, irrepetíveis, assim como intervir sobre elas em nome desses conhecimentos. Esse era o universo da certeza: as predições que não se cumpriam vinham a se converter em fontes de fracasso no que diz respeito à capacidade preditiva do conhecimento técnico. Pelo contrário, as intervenções técnicas baseadas em enunciados probabilísticos possuem uma forte proteção perante os eventuais acontecimentos que se afastem das predições, já que com elas se pode

2 Peter Berger, The Sacred Canopy, New York, 1967, citado por Beriain (1990). fundamentar o fracasso de uma explicação e/ou intervenção, não na certeza, mas na probabilidade, apenas, de acontecer o que fora anunciado: esse é o universo da incerteza, típico dos discursos e das práticas 
estruturadas em função do risco.

Sob essa consigna, o normal é percebido na certeza de que o futuro depende de decisões no presente. Na perspectiva de Luhmann (cf. 1992), por exemplo, isso não significa que, hoje, observar a distinção normal-divergente não conserve importância. O que interessa é saber que classe de compreensão, em termos de racionalidade, de decisão, de técnica, de futuro ou, simplesmente, de tempo, envolve a fala em torno do risco.

Nesse sentido, é preciso examinar um dos traços fundamentais dos discursos organizados segundo a lógica do risco e que se refere a suas propriedades enunciativas, aspecto que será abordado a seguir.

\section{O risco como sintaxe da vida social moderna}

O termo "risco" costuma denotar diversos sentidos, dependendo de quem o empregue e com que fim. A proliferação de diferentes usos, tanto no nível profano quanto no profissional, revela a existência de significados que chegam a ser confusos e de considerável complexidade (cf. Lupton, 1993). Mas, por que acontece esse fenômeno?

Em certa medida, isso é devido ao fato de a idéia de risco ter-se transformado num instrumento aberto à construção de múltiplos significados sociais. Na verdade, são as próprias características discursivas do risco as que geralmente introduzem um toque de opacidade para a análise sociológica. Sendo o risco uma construção primordialmente sócio-histórica, é geralmente concebido em termos não históricos. Assim, a idéia de risco tende a exibir a representação de um espaço social reduzido, na medida em que transporta uma fala despolitizada, isto é, no sentido da construção de imagens naturalizadas das condutas e das múltiplas manifestações da realidade social. O tipo de universo semântico que caracteriza a linguagem do risco é, então, limitado e fechado - atrás de fórmulas e diferentes tipos de cálculos de risco - a qualquer classe de interpelação, do ponto de vista dos conteúdos.

Com efeito, pelo fato de o risco ser uma construção que surge do campo da probabilidade, está investido de certo nível de invisibilidade. Possui assim um caráter contrafatual (cf. Giddens, 1991), orientado para o futuro e baseado em interpretações causais. Isso significa que, inicialmente, os riscos adquirem existência só no conhecimento (em princípio, científico), momento a partir do qual eles podem ser transformados, magnificados, dramatizados ou minimizados (cf. Beck, 1992).

A relativa invisibilidade dos riscos e sua dependência do saber científico-tecnológico indicam que a existência e distribuição social dos riscos estão mediatizadas por princípios inteiramente argumentativos que não fazem parte da experiência cotidiana do saber profano (cf. Beck, 1992).

Da mesma maneira que outros produtos do conhecimento, os 
enunciados científicos sobre risco, costumam ocultar, atrás de uma cortina de termos técnicos, um conjunto de crenças sociais, valores ou ideais políticos que, devido à sua inacessível sintaxe, resistem a qualquer forma de contraposição. Gera-se assim a possibilidade de que os discursos sobre o risco se percam num labirinto de símbolos, como adverte Norbert Elias, referindo-se a todas as formas de abstração modernas, “(...) pois os símbolos de um elevado nível de síntese não são em nossas sociedades frequientemente mais do que palavras vazias de conteúdo, palavras que perderam seu referente." (Elias, 1994, p. 37)

Essas características estariam na base dos fatores responsáveis pela transformação do conceito de risco num instrumento extremamente versátil para a gestão do social em geral, mediante uma classe de linguagem que garante a opacidade das dimensões axiológicas dos discursos e das práticas que organizam as respostas aos problemas sociais.

São atributos que fazem do risco um tipo de construção móvel, suscetível de circular no espaço social, de forma abrangente. Como já foi dito, o que fundamenta a possibilidade de um conjunto infinito de decisões e intervenções sobre a vida dos indivíduos não é simplesmente o que acontece e sim a probabilidade de que alguma coisa possa acontecer.

As propriedades discursivas do risco permitem-lhe agir como um dispositivo, num sentido muito próximo à definição foucaultiana. $\mathrm{E}$ entre as principais propriedades da noção de risco se destaca sua aptidão para o intercâmbio, aspecto que Elias descreve de maneira geral, para referir-se à totalidade de símbolos criados com funções de conhecimento:

"Num determinado período histórico suas redes de significação podem ser remodeladas com o fim de atingir uma simbolização melhor da que existia anteriormente. Aliás, estes símbolos podem se expandir ou declinar. Sua rede pode ser utilizada para abranger áreas de objetos ou para estabelecer conexões previamente não cobertas por eles e, portanto, inimagináveis e desconhecidas até então para os seres humanos, mas podem também languescer e se degradar até o ponto de que as áreas que cobriam podem chegar a ser novamente uma realidade desconhecida e inimaginável." (Elias, 1994, p. 54)

Nesse sentido, os discursos organizados sobre a idéia de risco podem ser amplamente utilizados para legitimar políticas ou para desacreditá-las; para proteger os indivíduos das instituições ou para proteger as instituições dos agentes individuais. A moralização e a politização dos perigos no contexto da modernidade exigem um vocabulário uniforme que já não pode ser o da religião, que estaria baseado nas idéias de pecado e de tabu. Em condições de modernidade, o risco possui a virtualidade de oferecer, segundo a expressão de Mary Douglas, "termos seculares para reescrever as sagradas escrituras" (1990, p. 5). 


\section{O risco como dispositivo biopolítico: tecnologia ou tecnopatia?}

Com a construção do enfoque de risco, um tipo de olhar e novas maneiras de lidar com os problemas sociais são instituídos. Nesse processo, o papel da internacionalização do saber e de um conjunto considerável de práticas tecnoburocráticas é fundamental. Pela gestão de organismos internacionais, o risco como conceito e como dispositivo não reconhece fronteiras nacionais ou culturais.

A discursividade em torno do risco passa a envolver todos os aspectos da vida humana, o que faz com que o indivíduo moderno experimente preocupações perante poucas coisas, “(...) exceto a comida que come, a água que bebe, o ar que respira, a terra na qual vive, e a energia que utiliza." (Douglas \& Widavsky, 1982, p. 10). Os riscos para a saúde, por exemplo, podem surgir em qualquer parte, sob a forma de ameaças freqüentes para a população (cf. Stoeckle, 1990). Aparecem permanentemente nos meios massivos de comunicação e são crescentemente objetos de campanhas públicas. A assessoria em riscos e a comunicação dos riscos têm se convertido em grandes indústrias. Em síntese: a idéia de risco tem adquirido um caráter proeminente no mundo ocidental, ao converterse em uma construção cultural central. (cf. Douglas, 1990).

Esse protagonismo recente estaria ligado aos novos significados que a noção de risco tende a assumir na percepção e gestão do social, além de conservar parte dos sedimentos semânticos originais. Isto obedece, em grande parte ao fato de que o risco passa a exercer novas funções sociais, ao ponto de se converter em um dispositivo biopolítico central da vida social contemporânea.

O que na atualidade é definido como o advento de uma nova questão social (cf. Rosanvallon, 1995) apresenta-se como um espaço adequado para conhecer o perfil das estratégias biopolíticas em condições de modernidade tardia. Em termos gerais, aquela pode-se definir pela emergência de novos fenômenos de exclusão, não redutíveis às antigas categorias de exploração e dominação e, simultaneamente, pela inadaptação dos velhos métodos de gestão do social a essa nova situação.

Nesse sentido, a crise do welfare state, que começou a ser diagnosticada há mais de vinte anos, ingressou mais recentemente em uma fase que Rosanvallon (cf. 1995) qualifica como crise filosófica. Experimenta-se uma crise que contém, segundo esse autor, dois problemas fundamentais: (I) a decomposição dos princípios organizadores da solidariedade, e (II) o fracasso das formas de gestão tradicionais - e das formas de conceber os direitos sociais, as quais se sustentam na construção de um marco satisfatório de superação das situações de exclusão social. Trata-se de uma inflexão decisiva na percepção do social que dominou durante quase um século o campo das políticas públicas e das 
políticas sociais e que, até certo ponto, corresponde ao ingresso em uma nova fase da modernidade.

As políticas sociais e, em particular, a seguridade social já não podem desempenhar o papel de centro aglutinador do bem-estar social. Agora, elas conseguem atingir apenas uma parte do campo social. Do ponto de vista do presente trabalho, não interessa discutir as origens nem as causas socioestruturais e políticas dessas mudanças. Interessa sim assinalar que, no que diz respeito às condições institucionais que nela participam, destaca-se o fato de se tratar de uma crise que, nas palavras de Rosanvallon (1995, p. 32), se caracteriza por gerar uma nova percepção da insegurança, no sentido de induzir uma relação diferente dos indivíduos com o Estado. Isto faz parte de uma transformação das pautas de integração social e de uma redefinição do papel do Estado.

Nas sociedades latino-americanas, assiste-se igualmente a uma desarticulação das antigas matrizes das políticas sociais, mediante transformações que atingem não só as orientações, mas também os mecanismos institucionais responsáveis pela regulação e a instrumentação de um vasto conjunto de serviços sociais. Nesse contexto, geralmente se reconhece a existência de uma passagem - até o presente, com resultados muito heterogêneos - de modelos de proteção social universais e centralizados para outros de natureza residual (cf. Titmuss, 1962), isto é, dirigidos às categorias e grupos em situações de risco ou marginalidade social.

Configura-se então uma mudança significativa que tem uma de suas expressões na substituição das políticas de integração, típicas do welfare state, pelas políticas de inserção, de acordo com a distinção empregada por Castel (1995). Essas últimas caracterizam-se pela focalização de um número crescente de grupos e categorias sociais que começam a ser classificados segundo déficits de integração, de acordo com interpretações substancialistas que destacam os atributos morais e psicológicos individuais na gestão das fragilidades e problemas sociais da contemporaneidade. Como aponta adequadamente Castel (1995), aparece uma tendência a exigir, precisamente dos indivíduos mais desestabilizados, que possam agir como sujeitos autônomos.

Do ponto de vista institucional, essas transformações podem ser também interpretadas como parte de uma nova forma de societalização, no sentido de uma metamorfose das relações indivíduo-sociedade (cf. Beck, 1992). Em certa medida, os processos de individualização estariam privando distinções de classe de sua identidade. Isso não significaria o desaparecimento das desigualdades sociais baseadas em clivagens tradicionais, e sim sua redefinição em termos de uma individualização dos riscos sociais: os problemas sociais passam a ser percebidos em função de disposições psicológicas e familiares. As crises sociais apresentam-se desse modo como crises individuais e, devido a isso, não são geralmente percebidas como ancoradas no domínio do social (cf. Beck, 1992). 
Nesse contexto, torna-se pertinente perguntar se esses novos parâmetros das relações indivíduo-sociedade exigem ou não uma renovação parcial ou total dos dispositivos que agem nos processos de arbitragem social e que fundaram a ordem social moderna.

Entre os dispositivos biopolíticos fundantes da modernidade e os dispositivos biopolíticos da modernidade como experiência contemporânea, podem ser registradas tanto mudanças quanto algumas permanências. Em termos hipotéticos, pode-se sugerir que, em condições de modernidade tardia e, particularmente, no caso da sociedade brasileira, no momento contemporâneo, observam-se justaposições entre formas mais ou menos renovadas de funcionamento dos dispositivos biopolíticos tradicionais com mecanismos inéditos de produção de saber e de exercício do poder no controle dos indivíduos e das populações. Os discursos e as práticas organizadas em torno da idéia de risco exibem de maneira paradigmática o convívio de antigas e novas formas de gestão do social. Isso responde ao fato dos dispositivos - e o dispositivo do risco não constitui nesse sentido uma exceção - serem, como adverte Foucault (1992), formações de natureza histórica, o que lhes confere, em cada circunstância, uma "função estratégica dominante".

Com a introdução da informática, ou seja, a partir do momento no qual os espaços de gestão política e administrativa são dotados de novos meios de trabalho, produz-se uma reorganização das bases materiais e simbólicas na detecção dos problemas sociais, tanto no nível dos indivíduos quanto no da população. Com efeito, o tratamento informático está baseado numa dissolução das particularidades dos indivíduos, as quais são obtidas na esfera clínica ou de relações interpessoais, para reter apenas um conjunto de dados abstratos em termos de fatores de risco, determinados e apresentados nos moldes dos interesses político-administrativos que possuem o controle do espaço público da gestão do social. Essas estratégias preventivas passam assim a economizar e reorganizar as relações interpessoais nas quais se sustentava a gestão da vida social, mediante uma nova divisão do trabalho que institui a criação de novas competências e, até certo ponto, uma requalificação dos papéis tradicionais dos agentes técnicos e burocráticos

Nessa direção, algumas análises levantam a hipótese de que a gestão de programas e formas de assistência organizados em torno do mapeamento dos riscos envolve, simultaneamente, a morte da clínica ou das relações interpessoais e sua substituição pelo estabelecimento de redes de comunicação e gerenciamento (cf. Haraway, 1991). Outras, menos radicais, percebem sintomas de uma progressiva perda de poder dos agentes clínicos ou assistenciais, uma vez que são instituídas as novas tecnologias baseadas na gestão tecnocrática das populações e dirigidas à prevenção dos riscos sociais (cf. Castel, 1981).

Precisamente, a gestão dos riscos requer, em muitos casos, a 
utilização combinada de ambos os tipos de estratégias: o gerenciamento político-administrativo da população, baseado no mapeamento dos riscos, e, simultaneamente, a individualização dos riscos enquanto condição de possibilidade de construção do mapa (cf. Castel, 1981; Rabinow, 1991).

\section{As tecnologias da atribuição e a individualização dos riscos}

Isso é possível porque o dispositivo do risco formaliza um conjunto de códigos que permitem transcrever os traços individuais, por meio de uma homogeneização que possui efeitos muito precisos: a criação de novos instrumentos de comparação e categorização sociais. Contudo, isso não significa que os instrumentos sejam aplicados sempre da mesma forma nem que respondam a uma mesma lógica. Na linha do que foi discutido com anterioridade, é importante lembrar que o risco tem-se convertido num instrumento versátil, isto é, de natureza polissêmica e, em decorrência disso, suscetível de ser objeto de diversos usos sociopoliticos.

Nesse sentido, torna-se necessário problematizar as formas que a atribuição dos riscos adota no momento contemporâneo. Com relação a esse ponto, pode-se concordar inteiramente com Luhmann (cf. 1992, p. 69), que enfatiza o caráter contingente das maneiras que a atribuição dos riscos assume: nesse registro, o que interessa, então, é identificar as tecnologias da atribuição e os fatores sócio-institucionais a elas associados.

No que diz respeito às maneiras de atribuição, diversas perspectivas sobre o risco podem ser achadas no interior de um mesmo instrumento. Assim, as diferentes representações sobre o risco responderiam à participação simultânea das duas classes de racionalidades que fazem parte do dispositivo e que se traduziriam - em termos gerais - na presença simultânea das concepções do risco como probabilidade e do risco como perigo, ou, em outras palavras, do risco como construção mental e do risco como ameaça real.

Ora, tanto se o risco é definido como perigo quanto se é definido como probabilidade, o indivíduo converte-se num alvo privilegiado das novas tecnologias de gestão da vida social. Por um lado, e da mesma forma que outras classes de exame, o dispositivo do risco permite manter a individualidade no interior de um campo documental, agora mediante uma renovação dos mecanismos de conhecimento e de poder, caraterizados pela tecnificaçäo e universalização de seus instrumentos. Trata-se de uma individualização descendente, já que, como adverte Foucault, “(...) a medida que o poder se torna mais anônimo e mais funcional, aqueles sobre os quais é exercido tendem a ser mais fortemente individualizados (...)" (1987, p. 197), por meio da vigilância e de observações padronizadas.

Paradoxalmente, observa-se a insistência em atribuir aos indi- 
MITJAVILA, Myriam. O risco como recurso para a arbitragem social. Tempo Social; Rev. Sociol. USP, S. Paulo, 14(2): 129-145, outubro de 2002.

víduos a responsabilidade pelas condutas de risco, ao mesmo tempo que tem diminuído o controle dos indivíduos sobre os riscos que provêm do ambiente. Por exemplo, o uso do discurso de risco na área da saúde pública - e, particularmente, na área da educação para a saúde - procura geralmente criar consciência pública sobre os riscos de saúde adquiridos nas opções feitas pelos indivíduos, no que se refere aos seus estilos de vida.

Nesse sentido, as descobertas da última década no campo da genética médica têm introduzido mudanças significativas na percepção dos riscos. Assim, por exemplo, Rabinow (cf. 1991) acredita que os dois pólos da biopolítica - indivíduo e população - são, na atualidade, objeto de uma rearticulação que possui origens nos avanços da medicina molecular. Em particular, ele examina o papel que pode desempenhar o Projeto Genoma (Human Genome Initiative) com relação aos registros interpretativos da etiologia das doenças, mas também no que diz respeito a outras condições físicas, mentais e sociais dos indivíduos. Com a identificação das bases genéticas de muitas doenças, começam a ser instituídas, no nível dos corpos individuais, novas formas de localização dos agentes patogênicos. Isso significa que, pelo menos hipoteticamente, a descoberta de pessoas com determinadas predisposições genéticas poderia conduzir a um amplo esquadrinhamento da população, quanto a um monitoramento das famílias e dos sujeitos "portadores" do problema. Certamente, esses indivíduos serão chamados a entender e a agir sobre seu próprio futuro, sob os parâmetros que a lógica do risco fornece.

No entanto, é necessário observar com prudência as novidades que introduzem as mudanças no saber científico e técnico, fundamentalmente no que diz respeito a seus desdobramentos potenciais sobre o conjunto do campo social. Trata-se de fenômenos muitos recentes para que se possam ponderar adequadamente sua significação e enraizamento sociais. Contudo, a literatura e a pesquisa em torno do tema apontam para o reconhecimento da expansão relativa da individualização dos riscos e, não poucas vezes, da responsabilização e culpabilização das pessoas.

Do ponto de vista dos objetivos do presente trabalho interessa sublinhar que a individualização dos riscos supõe o desenvolvimento de técnicas para incitar, orientar, informar e controlar os indivíduos e as famílias a respeito das chances de ocorrência de acontecimentos indesejáveis. É bom que se lembre da importância que assume a idéia de estilo de vida, como locus privilegiado para a construção das trajetórias biográficas na modernidade tardia. Nesse sentido, em nome dos riscos, os árbitros da vida social podem justificar intervenções dirigidas a vigiar, orientar, controlar, julgar e, ainda, punir os indivíduos e os setores de população que não conseguem construir - ou que opõem resistência à construção de - "estilos de vida saudáveis ou corretos". Quanto aos indivíduos, o risco pode-se converter no ponto de passagem obrigatório e imaginário 
para ter aceso ao próprio corpo e à própria identidade.

Assim, o risco começa a assumir, como dispositivo, novas funções sociais. E essas funções referem-se, de certa forma, ao que Mary Douglas (cf. 1990) chama de propriedades forenses do risco. Neste sentido, o risco pode agir:

- retrospectivamente, ao explicar os infortúnios individuais ou coletivos, em função das condutas do passado;

- para adiante, pela predição de recompensas futuras;

- e, poder-se-ia acrescentar, no presente, para fixar posições que habilitam tanto o acesso como as restrições que se impõem aos sujeitos nos mais variados campos da vida social (trabalho, educação, saúde, entre outros).

Exibem apropriadamente esse tipo de retórica sobre o risco os discursos que, perante um ataque cardíaco, um teste de HIV com resultado positivo e, ainda, uma doença oncológica, afirmam que a pessoa doente tem falhado no cumprimento das diretivas médicas recebidas para abater os riscos de adoecer, situação a partir da qual pode ser punida (com impedimento, por exemplo de acesso aos cuidados médicos) e/ou estigmatizada. Embora nem sempre aconteça, as propriedades arbitrais do risco abrem novas possibilidades para o desenvolvimento de estratégias de gestão do social. Assim, a emissão de juízos médicos sobre os estilos de vida - dos indivíduos ou de determinadas categorias sociais - começam a exercer arbitragens que acabam tendo consequiências para os indivíduos terem acesso, por exemplo, ao trabalho, aos seguros privados e, mesmo, aos cuidados médicos.

Em síntese, o dispositivo do risco contém duas dimensões estreitamente relacionadas entre si: a gestão técnico-burocrática das populações e a individualização dos riscos sociais. A unidade, como tem apontado Castel (1981), deverá provir da complementaridade de ambas as práticas, a partir de um pano de fundo institucional comum. Assiste-se, desse modo, a uma estratégia geral de gestão das diferenças, das fragilidades e dos riscos que parecem caraterizar as sociedades atuais.

Uma das características que podem ser reconhecidas no desenvolvimento do risco como dispositivo arbitral é o seu funcionamento ou capacidade para operar em termos auto-referidos. Por exemplo, o acesso dos setores pobres urbanos aos serviços e à assistência social passa a ser determinado, não em função das necessidades, direitos ou demandas presentes e imediatamente observáveis, e sim em função, unicamente, da probabilidade de, no futuro, apresentarem problemas específicos.

As políticas e programas sociais assim concebidos apresentam um apelo freqüente a critérios de eficiência. Dessa forma, a racionalização da provisão de serviços - por exemplo, pela extensão da cobertura encontra-se fortemente associada ao uso eficiente de recursos financeiros, materiais e humanos. Neste sentido, coloca-se geralmente a ênfase 
MITJAVILA, Myriam. O risco como recurso para a arbitragem social. Tempo Social; Rev. Sociol. USP, S. Paulo, 14(2): 129-145, outubro de 2002.

na utilização do enfoque de risco para promover atividades que impliquem baixa densidade tecnológica, como seria o caso da educação para a saúde e a participação comunitária (cf. Quesada \& Carro, 1991).

Destaca-se, então, o caráter instrumental que possuem as redes e sistemas de informação que são típicos desse modelo de gestão de riscos. Como aponta Castel (1981), as novas políticas preventivas economizam o caráter imediato das relações entre agentes dos serviços e sujeitos (individuais e coletivos) que são objetos de categorizações diagnósticas e de intervenções terapêuticas ou sociais. Assim, o que se deve tratar, num primeiro momento, não são os indivíduos e sim os fatores, as correlações estatísticas entre esses fatores. Trata-se de definir destinos homogêneos para indivíduos e setores de população que apresentam exposição a determinados riscos.

Com a introdução dos recursos informáticos, observa-se a participação de um novo tipo de racionalidade na detecção, ponderação, arbitragem e intervenção sobre os problemas sociais, que corresponde aos universos simbólicos, aos interesses e às culturas profissionais dos agentes que atuam nos campos da pesquisa, do planejamento e da direção de programas e serviços sociais. Apesar das diferenças que existem entre essas categorias, elas representam formas mais ou menos compartilhadas de aproximação aos fenômenos sociais, no sentido do desenvolvimento de pontos de vista que privilegiam o pólo populacional, seja para fins de detecção de riscos, seja para o planejamento de serviços e programas de prevenção ou assistência social.

Todavia, muitos são os problemas que se disparam a partir da introdução de instrumentos que trabalham no pólo oposto às maneiras estabelecidas de ver/enunciar/intervir que vigoram no coração da assistência direta. Os sistemas informáticos geralmente não contemplam os problemas de tradução referidos ao fato de se alimentarem de dados levantados no formato correspondente ao contexto assistencial, transferidos para um formato independente do contexto (gestão centralizada) (cf. Cicourel, 1985).

A literatura socioantropológica das últimas duas décadas tem gerado interessantes debates sobre os efeitos que a expansão desse pólo tecnoburocrático estaria gerando para a gestão dos riscos (cf. Castel, 1981; Haraway, 1991; Rabinow, 1991). Em vários desses trabalhos sugere-se que as novas tecnologias - em nosso caso, representadas pelo modelo tecno-instrumental - colocam uma ameaça para a autonomia dos operadores assistenciais e seus sistemas de trabalho, (e até mesmo para a sua sobrevivência), fundamentalmente no relativo ao monopólio para o desempenho de algumas funções e para a determinação dos meios de trabalho.

Contudo, no contexto empírico pesquisado, observou-se que o desenvolvimento do risco como dispositivo exige e, ainda, estimula a au- 
tonomia dos operadores de assistência direta. Porém, essa nova convivência de racionalidades diferentes (tecnopolítica e clínica) não está livre de conflitos nem se processa sempre em temos pacíficos.

A gestão moderna dos riscos exige, necessariamente, o desenvolvimento de processos de negociação entre representantes de racionalidades em confronto. Trata-se de negociações árduas, porém sempre possíveis, entre as formas padronizadas de registro de dados compatíveis com a vigilância da população e aquelas outras que são típicas do olhar clínico. Os operadores tecnoburocráticos muitas vezes encontramse a si próprios divididos entre as lealdades ao sistema de gestão tecnocrática dos riscos e seus compromissos com os representantes do espaço assistencial, este último sob sua responsabilidade técnica e/ou gerencial. Não obstante, sempre existiria a possibilidade de fazer compatíveis ambos os tipos de exigências, fundamentalmente devido à necessidade de preservar a integridade do sistema (seja a previdência social, um hospital ou um programa de combate à pobreza), em termos fundamentalmente corporativos, o que permite deter, enquanto tal, o controle desses dois espaços.

Um outro aspecto conflitante das relações entre as mentalidades clínica e tecnoburocrática reside na importância que esta última atribui à eficiência, como parte das argumentações tecnopolíticas para empreender programas sociais com enfoque de risco. Assim, em nome da eficiência, são justificadas medidas políticas dirigidas à racionalização dos recursos financeiros, materiais, humanos e técnicos vinculados à assistência social. A "ultra-tecnicalidade” - tomando aqui a expressão usada por Ayres (1995, p. 329) - desse modelo parece remeter com bastante freqüência ao papel do risco como fundamento para a provisão seletiva de serviços sociais, com baixa densidade tecnológica, no contexto de políticas focalizadas para setores em situação de pobreza e exclusão sociais.

Ora, a utilização do enfoque de risco para a provisão seletiva de serviços sociais (focalização) é apenas uma das virtualidades que exibe o modelo tecno-instrumental, entre outras possíveis classes de funções arbitrais. No mesmo sentido que já foi analisado no marco do presente trabalho, decidir se um indivíduo ou um setor da população pode ter acesso a outros benefícios (ajuda alimentar, ensino básico, por exemplo) passa a ser, por intermédio das práticas promovidas pelo modelo tecno-instrumental, muito mais o resultado de uma arbitragem tecnoburocrática que o resultado de direitos sociais adquiridos por esse indivíduo ou população. Um exemplo disso é a distribuição da cesta básica de alimentos entre as mães que levam seus filhos à consulta pediátrica (recompensa) ou, caso contrário, a retirada desse benefício às mães que não comparecem ao serviço de saúde (punição).

Poder-se-ia argumentar que a moderna gestão dos riscos, ao 
MITJAVILA, Myriam. O risco como recurso para a arbitragem social. Tempo Social; Rev. Sociol. USP, S. Paulo, 14(2): 129-145, outubro de 2002.

promover o autocuidado e defender os benefícios que isso representa para o autogoverno dos indivíduos, abre portas para pensar, em termos potenciais, nas propriedades emancipatórias do dispositivo. Porém, nenhum dos dispositivos biopolíticos até agora conhecidos existe em si mesmo: o risco é pura forma e não conteúdo; ele permanece aberto, disponível para circular abrangentemente no espaço social e oferecer assim um suporte para transportar múltiplos projetos e significados sociais. Com o declínio relativo das estratégias punitivas e a expansão do campo de objetos das estratégias arbitrais, se converterá o risco no obrigatório ponto de passagem para os indivíduos terem acesso a um controle maior sobre a própria biografia? A resposta deveria ser negativa, porque o risco, como toda construção social, como disse Lévi-Strauss com relação aos mitos, não existe "no absoluto".

Recebido para publicação em agosto/2002

MITJAVILA, Myriam. Risk: a new device for social arbitration. Tempo Social, Rev. Sociol. USP, S. Paulo, 14(2): 129-145, October 2002.

ABSTRACT: In the last two decades, social sciences have been registering and analyzing the growing appearance of a new way to codify the dangers and threats that characterize social life in contemporary societies. This consists of the proliferation of discourses and technical/ political practices organized in function of risk. We can observe that there exists consensus in the sociological literature about the definition of risk as social construction and the complex relationships between risk and scientific - technical knowledge. This work especially discusses the socio - technical and institutional bases of risk as a device for arbitrage of social problems in such diverse levels as the selective provision of social services, determination of guilt and/or danger in criminal behavior, allowance of credits in the financial system, management of human resources in the labor area, and others.

\section{REFERÊNCIAS BIBLOGRÁFICAS}

Ayres, José Ricardo de Carvalho Mesquita. (1995) Epidemiologia e emancipação. São Paulo, Hucitec/ Rio de Janeiro, Abrasco.

BECK, Ulrich. (1992) Risk society. Towards a new modernity. London, Sage Publications.

KEYWORDS:

risk, social arbitrage, new health practices. 
. (1997a) La reinvención de la política: hacia una teoría de la modernización reflexiva. In: Giddens \& Lash. Modernización reflexiva: política, tradición y estética en el orden social moderno. Madrid, Alianza, p. 16-73.

. (1997b) Réplicas y críticas. In: , Giddens \& Lash. Modernización reflexiva: politica, tradición y estética en el orden social moderno. Madrid, Alianza, p. 209-219.

Berger, Peter et alii. (1979) Un mundo sin hogar. Modernización y conciencia, Santander, Sal Terrae.

BerIaIN, Josetxo. (1990) Representaciones colectivas y proyecto de modernidad. Barcelona, Anthropos.

CAStel, Robert. (1981) La gestion des risques. De l'antipsichiatrie a l'aprés-psychanalyse. Paris, Éditions du Minuit. . (1995) Les metamorphoses de la question social. Paris, Fayard.

Cicourel, Aaron Victor. (1985) Raisonnement et diagnostic: le rôle du discours et de la comprénsion clinique en médecine. Actes de la Recherche en Sciences Sociales, 60: 79-89.

Douglas, Mary. (1990) Risk as forensic resource. Daedalus, 119(4): 1116.

. (1996) Cómo piensan las instituciones. Madrid, Alianza.

\& Wildavsky, Aaron (1982) Risk and culture. Oxford, Basil Blakwell.

Elias, Norbert. (1994) Conocimiento y poder. Madrid, La Piqueta.

Foucault, Michael. (1987) Vigilar y castigar. Nacimiento de la prisión. México, Siglo XXI.

. (1992) Poder-corpo. In: Machado, Roberto. (org.). Microfísica do poder. Rio de Janeiro, Graal, p.145-152.

GidDENs, Anthony. (1991) As conseqüências da modernidade. São Paulo, Editora Universidade Estadual Paulista.

. (1995) Modernidad e identidad del yo. El yo y la sociedad en la época contemporánea. Barcelona, Ediciones Península.

Haraway, Donna Jeanne. (1991) The biopolitics of postmodern bodies: constitutions of self in immune system discourse. In: Simians cyborgs and women. The reinvention of nature. New York, Routdledge.

Laplantine, François. (1991) Antropologia da doença. São Paulo, Martins Fontes.

Lash, Scott \& Wynne, B. (1992) Introduction. In: Beck, Ulrich. Risk society. Towards a new modernity. London, Sage Publications. 
MITJAVILA, Myriam. O risco como recurso para a arbitragem social. Tempo Social; Rev. Sociol. USP, S. Paulo, 14(2): 129-145, outubro de 2002.

LuHMANN, Niklas. (1992) Sociología del riesgo. Guadalajara, Universidad Iberoamericana / Universidad de Guadalajara.

LuPTON, Deborah. (1993) Risk as moral danger: the social and political functions of risk discourse in public health. International Journal of Health Services, 23: 425-435.

Martin, E. (1992) The end of the body? American Ethnologist, 19(1): 121-140.

Mitjavila, Myriam. (1999) O risco e as estratégias de medicalização do espaço social: medicina familiar no Uruguai (1985-1994). São Paulo. Tese (Doutorado). Faculdade de Filosofia, Letras e Ciências Humanas da Universidade de São Paulo.

Quesada, G. \& CARro, M. (1991) Enfoque sistémico en la evaluación de servicios materno infantiles. Atención Primaria de Salud, Montevideo, 12: 2-18.

RaBınOw, Paul. (1991) Artificialidade e ilustração. Da sociobiologia à bio-sociabilidade. Novos Estudos, 31: 79-93.

Rosanvallon, Pierre. (1995) La nueva cuestión social. Repensar el Estado providencia. Buenos Aires, Ediciones Manantial

SAntos, B.S. (1995) A construção multicultural da igualdade e da Diferença. Palestra proferida no VII Congresso Brasileiro de Sociologia. Universidade Federal de Rio de Janeiro.

TITMUss, Richard Morris.(1962) Income distribution and social change. London, Allen - Unwin. 